\title{
Pulsed Laser Welding between DP1000 Steel and Aluminum Alloy 1050
}

\author{
António B. Pereira ${ }^{1 *}$, Ana Cabrinha ${ }^{1}$, Fábio Rocha ${ }^{1}$, Pedro Marques ${ }^{1,2}$, \\ Fábio A. O. Fernandes ${ }^{1}$ and Ricardo J. Alves de Sousa ${ }^{1}$
}

DOI:

\begin{abstract}
The welding of dissimilar metals was carried out using a pulsed Nd: YAG laser to join DP1000 steel and an aluminum alloy $1050 \mathrm{H} 111$. Two sheets of each metal, with $30 \times 14 \times 1 \mathrm{~mm}^{3}$, were lap welded, since butt welding proved to be nearly impossible due to the huge thermal conductivity differences and melting temperature differences of these materials. The aim of this research was to find the optimal laser welding parameters based on the mechanical and microstructure investigations. Thus, the welded samples were then subjected to tensile testing to evaluate the quality of the joining operation. The best set of welding parameters was replicated, and the welding joint obtained using these proper parameters was carefully analyzed using optical and scanning electron microscopes. Despite the predicted difficulties of welding two distinct metals, good quality welded joints were achieved. Additionally, some samples performed satisfactorily well in the mechanical tests, reaching tensile strengths close to the original 1050 aluminum alloy. The possibility to effectively join high strength dual-phase steels with a soft, ductile 1XXX aluminum alloy opens a new range of design possibilities and attests the versatility of laser-type welding operations. The authors hope that this study can serve as a sounding base for any other future work in this area.
\end{abstract}

Keywords: Laser welding; pulsed Nd:YAG laser; DP1000 steel; 1050 aluminum alloy; dissimilar materials welding; steel/aluminum joint.

\section{INTRODUCTION}

Currently, there is a growing interest across various industries to join different metals or alloys [1,2]. This interest is justified by the flexibility that such options would provide in terms of mechanical project and design, for instance, by utilizing high-quality alloys for critical structural points and low-quality ones for less significant areas. Among the many manufacturing technologies, joining has been identified as a key enabling technology to innovative and sustainable manufacturing [3,4]. Additionally, considering for instance the automotive industry, this solution makes it possible to manufacture lighter components [5-8]. This would also significantly reduce fuel consumption, thereby reducing $\mathrm{CO}_{2}$ emissions, which is of the utmost importance in complying with environmental demands and policies, and also to improve manufacturers/brands in their green marketing campaigns. The use of aluminum alloys and steels for some of sensitive components is relatively influenced by the current regulations to encounter fuel efficiency standards [9-11].

Steel and aluminum are two materials that are extremely difficult to join by welding. They have different chemical compositions, as well as physical and mechanical properties, which translates into a homogeneity problem. These materials have completely different melting points. Aluminum can melt during the welding process, whereas steel can remain solid [2]. In other words, the laser power necessary to melt steel is excessive for aluminum. On the other hand, aluminum's reflexivity and the

\footnotetext{
${ }^{1}$ TEMA-Centre for Mechanical Technology and Automation, Department of Mechanical Engineering, University of Aveiro, Campus de Santiago, 3810-193, Aveiro, Portugal.

${ }^{2}$ Industrial Engineering and Management, Universidade Lusófona, Campo Grande 376, 1749, Lisbon, Portugal.

${ }^{*}$ Corresponding author: E-mail: abastos@ua.pt;
} 
high melting temperature of the oxides present on its surface make its melting quite difficult. Thus, specific welding strategies must be adopted in order to properly weld these materials.

Moreover, the thermal conductivities and thermal expansion coefficients of steel and aluminum alloys are also completely different, which makes welding of these materials a true challenge [6-8]. Therefore, during the welding process, thermal stresses and residual stresses develop on the welding joint [2]. Additionally, the occurrence of intermetallic compounds (IMCs) of Fe-Al on the welding joint during solidification is possible [12]. IMCs are very hard and fragile, decreasing the joint tenacity and plasticity of the joint, i.e., basically turning it brittle [2]. The IMC layers formation is highly dependent on the temperature and time [13], which must be controlled to successfully join steel and aluminum [14]. Consequently, there is a series of problems in joining these two materials, and some solutions have been proposed. Torkamany et al. [15] reported a successful welding of low-carbon steel ST14 (0.8 $\mathrm{mm}$ thick) and 5754 aluminum alloy $(2.0 \mathrm{~mm}$ thick), using a pulsed Nd:YAG laser. It was found that the power and pulse duration had an influence on the welding process. Torkamany et al. [15] reported the expected formation of IMCs. An increase in both parameters meant an equal increase in the terms of the IMCs formation. Moreover, with the increase in laser power, the extent of spatter, cracks, and pores also increased. On the other hand, for low laser power values, penetration was insufficient. Sun et al. [16] studied weld butt joints between Q235 low-carbon steel and an AA6013 aluminum alloy, also using an Nd:YAG laser and adding the aluminum alloy 4043 as filler material. As in Reference [15], the formation of the IMCs: $\mathrm{Fe}_{2} \mathrm{Al}_{5}$ and $\mathrm{FeAl}_{3}$ occured. Failure analysis of the joints showed a typical cleavage-type fracture with crack initiation starting within the $\mathrm{FeAl}_{3}$ phase. The maximum registered tensile strength of the joint was $120 \mathrm{MPa}$.

These were the most recent and relevant studies found in the literature. Other authors have used fusion-brazing welding [17] or dual laser beam fusion welding [14] or even explosion welding [18-20], which are relatively if not widely different from the investigation at hand, especially the latter. Nevertheless, despite considering these techniques, we did not find any study relating to DP1000 steel and aluminum alloy 1050 welding. In fact, even in well performed literature reviews by Sun and Ion [1], Wang et al. [2], Shah and Ishak [4] and Katayama [21], no study was found regarding the laser welding of these metals. In this work, the authors aimed to determine the optimal set of laser welding parameters, based on mechanical testing and microstructure investigations.

Nowadays, laser technology is used in many applications. Concerning mechanical technology, this can be used to perform precise welding or even precise cutting of high strength steels [22,23]. Laser welding is a joining method that is still relatively recent and makes it possible to obtain better results compared to other welding technologies. This is the main reason behind the replacement of resistance spot welding in several industries. For instance, considering the automotive industry, laser welding has been extensively used, since it makes it possible to perform smaller welding joints (small heat-affected zone) with higher precisions, penetrations, and flexibility. Additionally, it only requires one side of the base metal to accomplish the joining process and it is a technique characterized by high welding speeds, making it an excellent alternative to the conventional welding processes [2,24]. Currently, laser welding is widely used in metals such as titanium alloys $[25,26]$ and dual-phase steels [27].

\section{MATERIALS AND METHODS}

\subsection{Laser Welding Machine}

The machine used was a SISMA SWA300, Fig. 1a. The Nd:YAG laser uses, as an active medium, a crystalline solid made of Nd:YAG (neodymium-doped yttrium aluminum Garnet - Y3AI5O12). A parametric study was performed to find a set of welding parameters that made it possible to obtain quality welding joints between DP1000 steel and 1050 aluminum alloy. To evaluate the welded samples, the same methodology adopted in a previous study was also adopted [27], as well as performing tensile and microhardness tests.

The SISMA SWA300 was primarily designed to perform mold reparation and maintenance, with or without the use of a filler material. Since this machine was designed for mold reparation, it does not 
have an original fixation system. Thus, a simple and effective solution was designed as depicted in Fig. 1b.
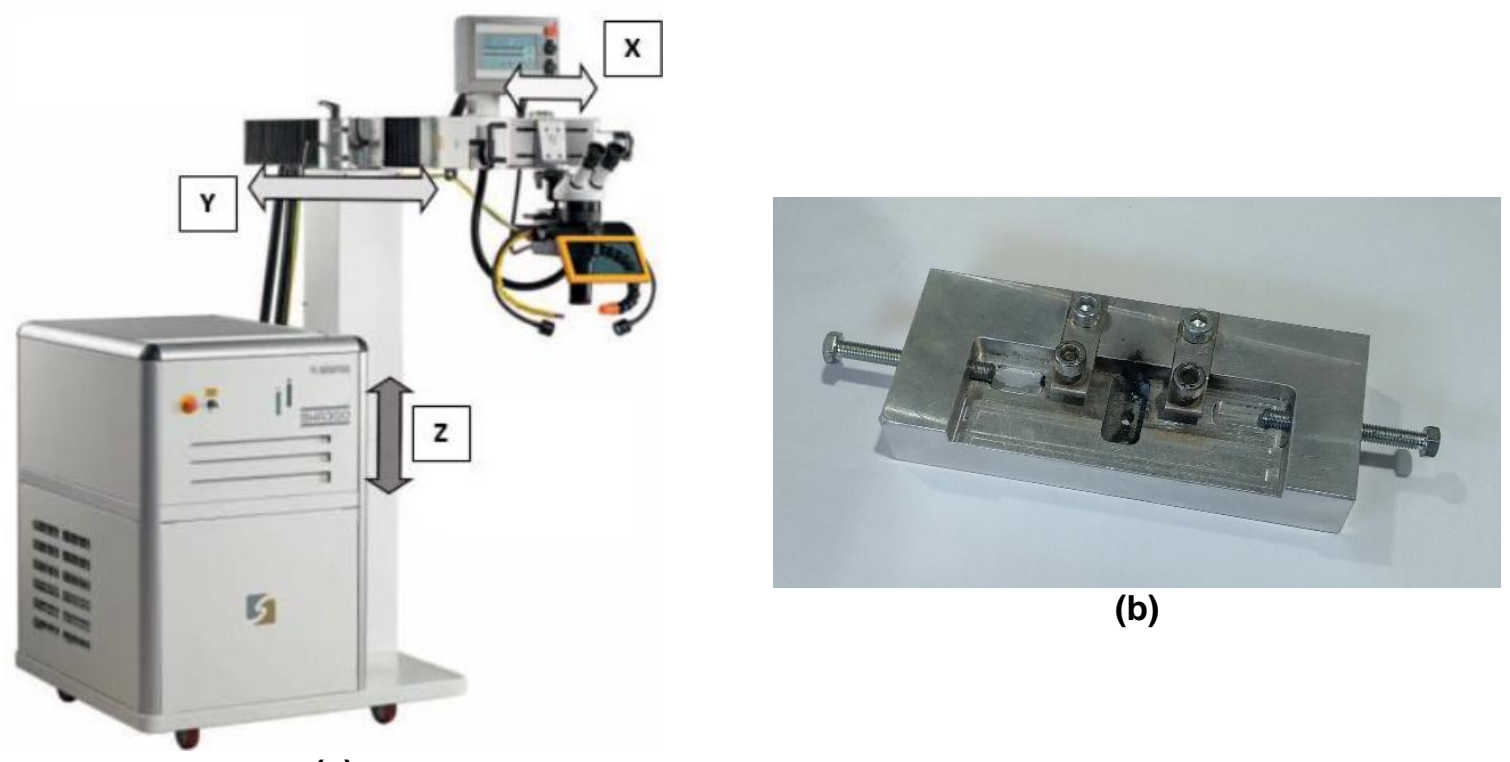

(b)

(a)

Fig. 1. (a) SISMA SWA300 Nd:YAG laser welding machine; (b) Fixation/support system

The support system has a hole for inserting the protection gas tube. From left to right, Fig. 2 illustrates the procedure necessary to properly fix the samples. The first step was to insert the protection gas tube, ensuring that the protective gas was properly covering the samples. The second step consisted of putting the samples in their positions. In order to perform lap welds, a third metal sheet with the same thickness was placed under the top one, which meant it was under the steel sample. The third step was to ensure that both parts were properly placed, using screws at the sides. The last step was to guarantee the complete fixation by using the upper screws, thereby closing the gap between the metal sheets as much as possible.
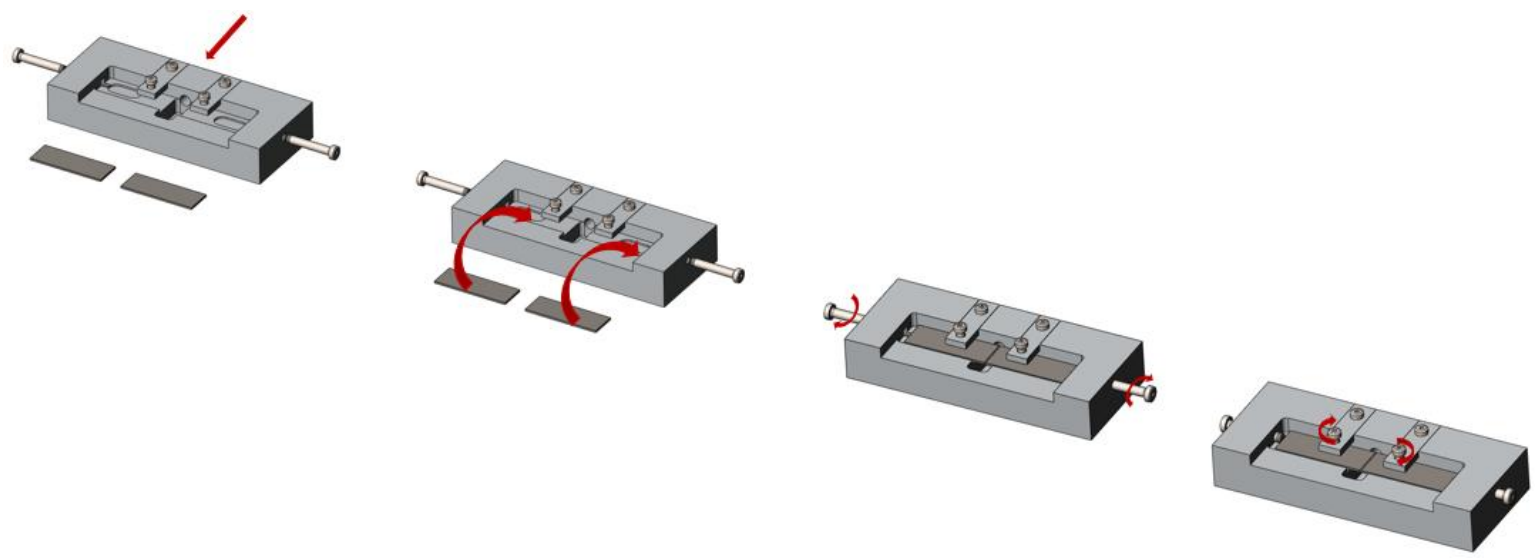

Fig. 2. Illustration of the support/fixation system operation

In order to prevent oxidation, an isolating box was designed and placed on this device. This box was made of glass, due to its transparency and its better thermal resistance (compared to acrylic). Fig. 3 shows the glass parts that were glued to create the referred to protective box, for use during the joining process. The protection gas used was Argon ARCAL TIG MIG, supplied by Air Liquide. 

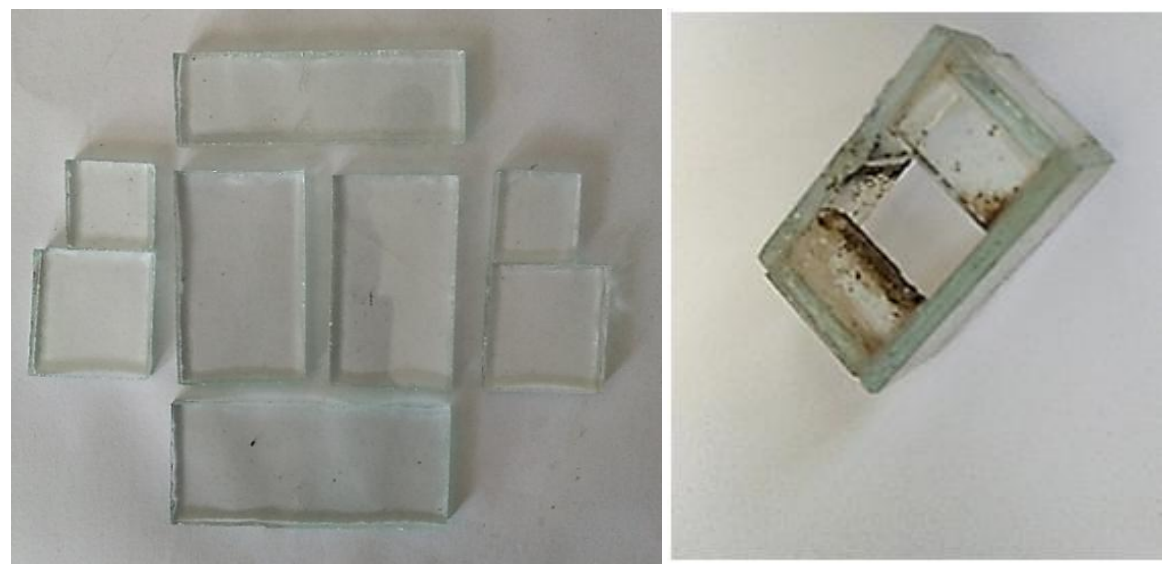

Fig. 3. Isolating glass box

\subsection{Materials and Samples}

As described, the dissimilar metals chosen were the DP1000 steel and the AA1050 aluminum alloy $\mathrm{H} 111$. Both samples had a thickness of $1 \mathrm{~mm}$ and dimensions of $30 \mathrm{~mm} \times 14 \mathrm{~mm}$. The $1 \mathrm{~mm}$ thick samples were cut using a Guifil guillotine.

These materials had completely different melting points. Table 1 presents a simple comparison between iron and aluminum. Aluminum can melt during the welding process, whereas steel can remain solid [2]. In other words, the laser power necessary to melt steel was overly excessive compared to the aluminum. Therefore, the welding was performed only on the steel part, whilst slightly penetrating the aluminum one, without destabilizing it. Tables 2 and 3 present the chemical compositions of both materials.

Table 1. Properties of the Fe and Al at room temperature [28]

\begin{tabular}{llllll}
\hline Metal & $\begin{array}{l}\text { Melting } \\
\text { temperature }[\mathrm{K}]\end{array}$ & $\begin{array}{l}\text { Density } \\
{\left[\mathrm{kg} \cdot \mathrm{m}^{-3} \text { ] }\right.}\end{array}$ & $\begin{array}{l}\text { Thermal } \\
\text { conductivity } \\
{\left[\mathrm{W} \cdot \mathbf{m}^{-1} \cdot \mathrm{K}^{-1} \text { ] }\right.}\end{array}$ & $\begin{array}{l}\text { Specific heat } \\
\text { capacity } \\
{\left[\mathbf{J} . \mathbf{k g}^{-1} \cdot \mathrm{K}^{-1}\right]}\end{array}$ & $\begin{array}{l}\text { Thermal } \\
\text { expansion } \\
\text { coefficient }\left[\mathrm{K}^{-1} \text { ] }\right.\end{array}$ \\
\hline $\mathrm{Fe}$ & 1809 & 7870 & 78 & 456 & $12.1 \times 10^{6}$ \\
$\mathrm{Al}$ & 933 & 2700 & 238 & 917 & $23.5 \times 10^{6}$ \\
\hline
\end{tabular}

Table 2. Chemical composition of the AA1050 aluminum alloy [wt.\%] [29]

\begin{tabular}{lllllll}
\hline Ti & Zn & Mn & Fe & Si & Mg & Cu \\
\hline 0.05 & 0.07 & 0.05 & 0.4 & 0.25 & 0.05 & 0.05 \\
\hline
\end{tabular}

Table 3. Chemical composition of DP1000 steel [wt.\%] [30]

\begin{tabular}{lllllllll}
\hline $\mathbf{C}$ & $\mathrm{Si}$ & $\mathrm{Mn}$ & $\mathbf{C u}$ & $\mathrm{Al}$ & $\mathbf{C r}$ & $\mathbf{N i}$ & $\mathbf{N b}$ & $\mathbf{V}$ \\
\hline 0.141 & 0.49 & 1.47 & 0.02 & 0.041 & 0.03 & 0.04 & 0.016 & 0.01 \\
\hline
\end{tabular}

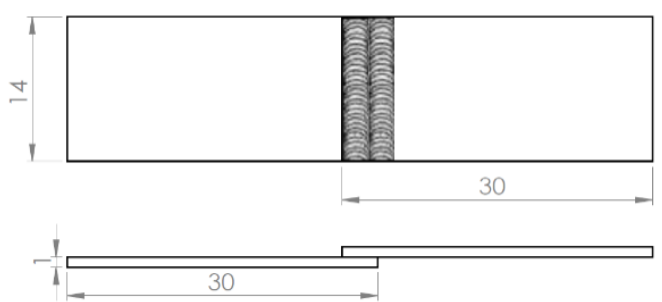

Fig. 4. Schematic of the welding performed on the samples 
The samples were lap welded with the steel on top (Fig. 4). It was verified that as the welding progressed, naturally the samples would heat, and the penetration would increase longitudinally. Thus, for the second welding joint, the sample was rotated $180^{\circ}$ and the welding process proceeded in the same direction. This way, less penetration achieved on the initial regions of the first welding joint would be compensated by the second, which would accomplish just that.

\subsection{Laser Welding Parameters}

Regarding the laser parameters that could be analyzed using the SISMA SWA300, the following parameters were considered: Laser power (percentage of peak pulse); pulse duration; frequency/superposition; and laser beam diameter. Since there was no data in the literature regarding DP1000-AA1050 aluminum welding, the ideal welding parameters were found by trial and error, as well as taking into consideration the conclusions of other studies previously carried out using the same machine. From these conclusions, the following were considered:

Laser beam power: The penetration was proportional to the laser beam power. The ideal values were situated between $6 \mathrm{~kW}$ and $7.20 \mathrm{~kW}$ of the maximum peak power of $12 \mathrm{~kW}$.

Pulse duration: The penetration was also proportional to higher pulse durations. Previous values were between 12-16 ms.

Superposition: It did not influence penetration until values around $80 \%$.

Laser beam diameter: The penetration seemed to be inversely proportional to the welding spots diameter. A constant value of $1 \mathrm{~mm}$ was used.

Welding speed: A high welding speed meant high penetration. The speed was then limited by the amount of power/energy and pulse duration used. For higher values of pulse duration and/or power (and thus energy), smaller values of speed were allowed for a proper welding process.

Similar to Torkamany et al. [15], which evaluated the influence of power and pulse duration on the welding process, in the first stage, only power was varied to find its ideal value. Then, other parameters were changed based on visual analysis and tensile testing. This evolution regarding the welding parameter values is described thoroughly in the results section.

Table 4. Parametric study for steel-aluminum welding

\begin{tabular}{lll}
\hline Sample & Power [kW] & Pulse duration [ms] \\
\hline 1 & 8.40 & 14 \\
2 & 7.20 & 14 \\
3 & 7.08 & 14 \\
4 & 6.96 & 14 \\
5 & 6.84 & 14 \\
6 & 6.72 & 14 \\
7 & 6.60 & 14 \\
8 & 6.48 & 14 \\
9 & 6.36 & 14 \\
10 & 6.24 & 14 \\
11 & 6.12 & 14 \\
12 & 6.00 & 14 \\
13 & 6.48 & 16 \\
14 & 6.48 & 15 \\
15 & 6.48 & 13 \\
16 & 6.48 & 12 \\
17 & 6.48 & 11 \\
18 & 6.60 & 13 \\
19 & 6.60 & 15 \\
20 & 6.60 & 16 \\
\hline
\end{tabular}


Table 4 shows the parameter values used for each welded sample. A square wave was defined as the pulse type for all the samples. The welding speed was the lowest possible concerning machine restrictions, because for higher values, the penetration on the aluminum sample would be excessively high, destroying any chance of a properly welded joint. Additionally, a constant laser beam diameter and superposition of $1 \mathrm{~mm}$ and $60 \%$ were used, respectively.

\subsection{Tensile Testing}

To determine the mechanical properties of the welded samples, mainly the tensile strength and respective deformation of each set of parameters, tensile testing was performed using a Shimadzu 10 kN machine (Fig. 5).

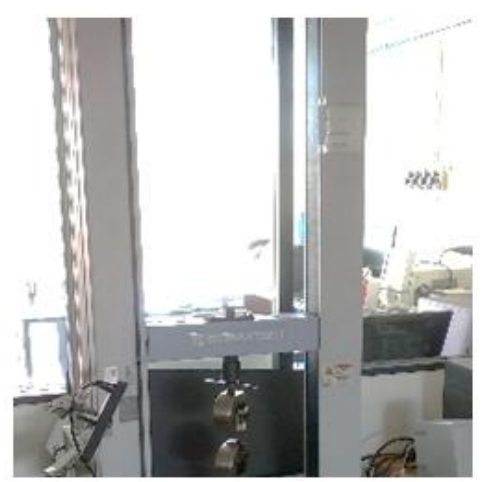

Fig. 5. Shimadzu $10 \mathrm{kN}$ tensile testing machine

Considering lap welding, deflection phenomena are expected to occur during tensile testing. We then used the following equation to compute stress:

$$
S=\frac{F}{A_{0}}+\frac{M x \times y}{I x},
$$

where $F$ is the magnitude of the forces applied, $A_{0}$ is the initial cross section area of the joint, $M_{x}$ and $I_{x}$ are the torque and moment of inertia about the $X$-axis, respectively, and $y$ is the maximum distance about the $\mathrm{Y}$-axis considering a $\mathrm{xOy}$ plane as follows:

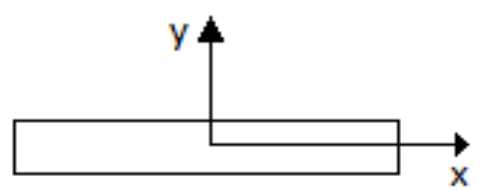

Fig. 6. Illustration of $x O y$ plane on the sample

Since the superposition of the welding spots had a value of $60 \%$, the area of the joint was approximated to one of a $14 \times 1 \mathrm{~mm}^{2}$ rectangle. However, the deflection stresses were negligible $(<1,5 \mathrm{MPa}$ on every test) due to the small dimensions of the samples. Thus, in order to determine the nominal stress, we used the following approximation:

$$
S \approx \frac{F}{A_{0}},
$$

where $S$ is the nominal stress, $F$ is the magnitude of the applied force, and $A_{0}$ is the cross-sectional area of the sample (since fracture should occur on the aluminum part). The normal strain was determined through:

$$
e=\frac{\Delta L}{L_{0}},
$$


where $e$ is the nominal deformation, $\Delta L$ is the change in length, and $L_{0}$ is the original length considered for the sample at hand, in this case it was $30 \mathrm{~mm}$ for each test. The true stress was calculated by:

$$
\sigma=S(1+e),
$$

where $\sigma$ is the true stress, whilst the true strain $\varepsilon$ was determined as:

$$
\varepsilon=\ln (1+e),
$$

\subsection{Microstructure}

For a deeper analysis of the welding, a new sample based on the optimum welding parameters found in the tensile testing was re-created to analyze its microstructure. Firstly, the sample was transversely cut for the observation of a substantial part of its welding joint, as well as longitudinally, to have a 25 $\mathrm{mm}$ length to fit the mold (Fig. 7). Cutting was precisely performed using a Struers cutting machine.

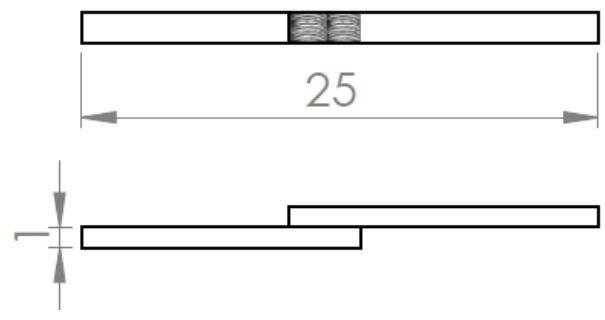

Fig. 7. Illustration of the sample for microstructural observation

After this, the sample was inserted on a cylindrical mold of $25 \mathrm{~mm}$ diameter and then epoxy resin was injected into it, as well as a hardener. Once solidified (Fig. 8), the injected sample was removed from the mold and then polished for observation. Polishing diamond papers $(3 \mu \mathrm{m})$ of $180,320,800,1200$, 2500 and 4000 grit were used. The machine used was a rotary polishing machine, the Struers RotoPol-21 machine.

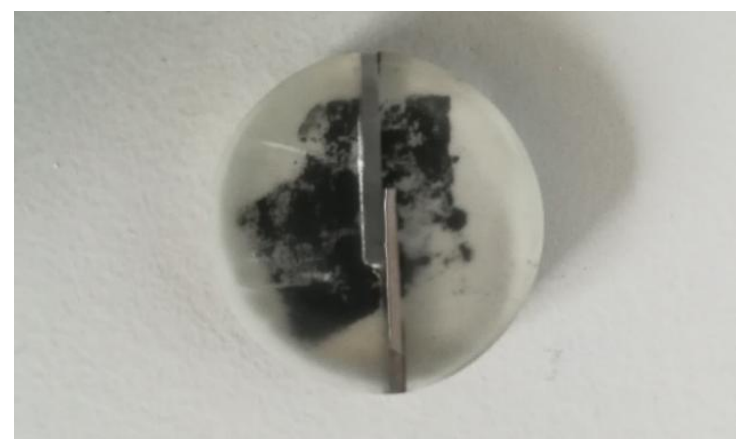

Fig. 8. Solidified sample after injection of epoxy resin + hardener

Then, the injected sample was subjected to chemical etching using nital (4\%) (Ethanol + Nitric Acid), to help the microstructure observation. The nital etching was executed, lasting 20 seconds. At first, it was also subjected to a Keller's reagent $\left(\mathrm{HNO}_{3} 2.5 \mathrm{~mL} ; \mathrm{HCl} 1.5 \mathrm{~mL} ; \mathrm{H}_{2} \mathrm{~F}_{2} 1 \mathrm{ml}, \mathrm{H}_{2} \mathrm{O} 95 \mathrm{ml}\right)$. However, it would cause oxidation due to the iron $(\mathrm{Fe})$ present in the sample, complicating the observation. Thus, at the end, only the nital etching was considered. The microstructural observations were performed using an optical microscope and a scanning electron microscope (SEM) with an integrated back-scattered electron detector (BSE). Elemental composition mapping was performed using an energy-dispersive X-ray spectroscopy (EDS). 


\section{RESULTS}

\subsection{Laser Welding}

Considering the values presented in Table 4 for each welded sample, after tensile testing, it was verified that considering the speed used, the ideal interval was from $6 \mathrm{~kW}$ to $7.20 \mathrm{~kW}$. More specifically, the best performance on tensile testing was achieved at a laser power of $6.48 \mathrm{~kW}$ (sample eight from 12 samples, Table 4). It became clear that for welding powers higher than 7.20 $\mathrm{kW}$, the laser would fully penetrate the aluminum part, resulting in brittle joints, which were easily breakable by hand. Then, the duration of the pulse was altered, and the laser power fixed (samples 13 to 16). On the final samples (17 to 20), these two parameters were slightly changed from the ideal values. Fig. 9 presents the 20 welded samples.

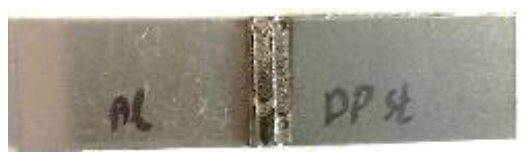

(1)

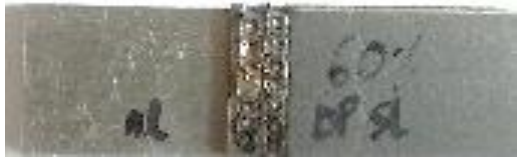

(2)

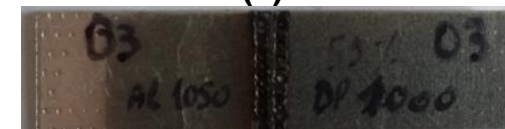

(3)

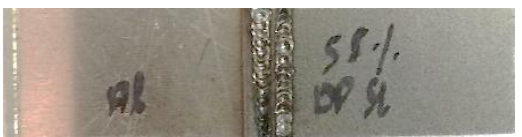

(4)

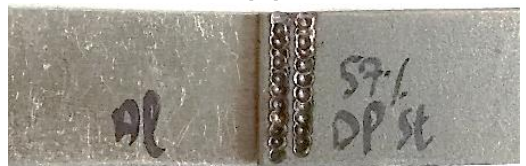

(5)

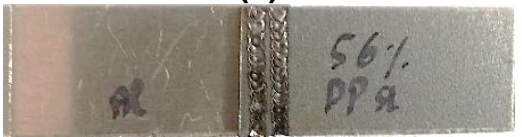

(6)

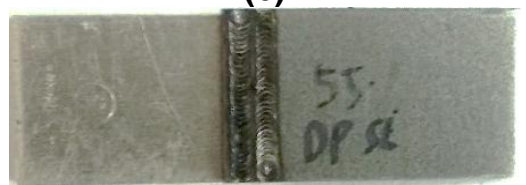

(7)

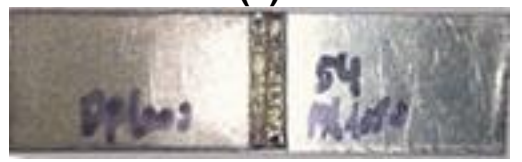

(8)

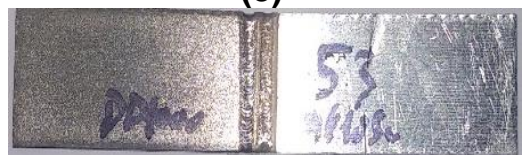

(9)

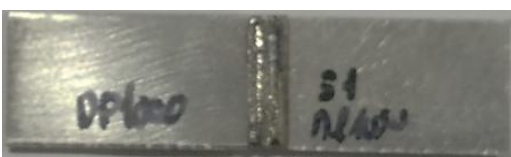

(11)

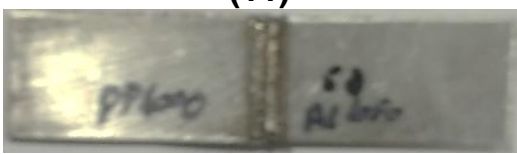

(12)

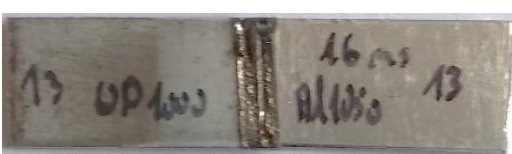

(13)

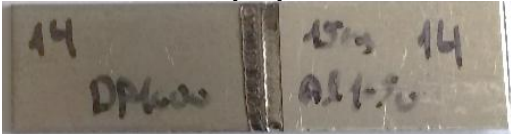

(14)

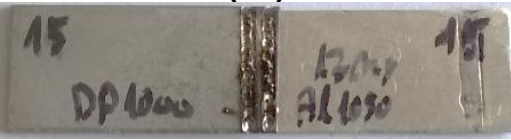

(15)

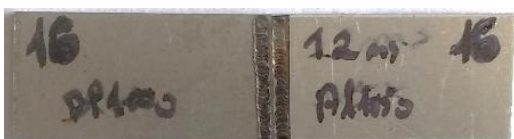

(16)

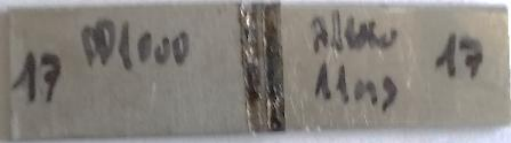

(17)

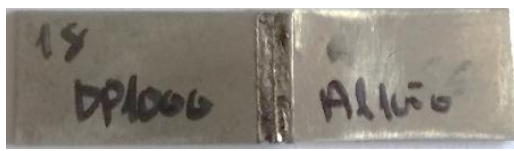

(18)

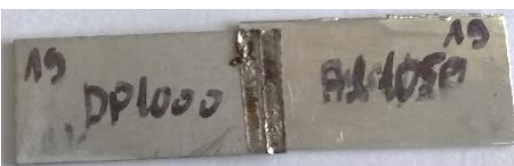

(19) 


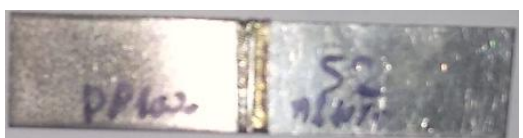

(10)

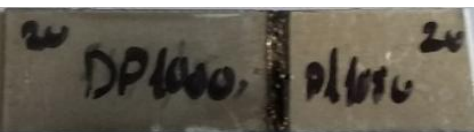

(20)

Fig. 9. Steel-aluminum welded samples

\subsection{Tensile Testing}

Fig. 10 presents the samples after tensile testing, as well as a reference sample made of aluminum $(60 \times 14 \mathrm{~mm})$, since ideally, the fracture occurs on the aluminum part, due to its lower tensile strength. We considered the normalization of this reference sample. Nevertheless, it was not done for a better similarity with the welded samples. Additionally, it is worth mentioning that sample 20 was not subjected to tensile testing, since we noticed that the laser significantly penetrated the aluminum, with some wide penetrations in some regions. Therefore, the sample would fracture easily while testing, producing negligible data. Thus, this specific sample was removed from the experiment.

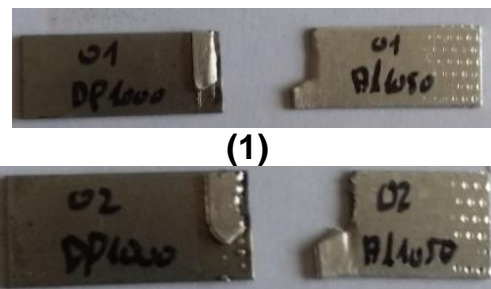

(2)

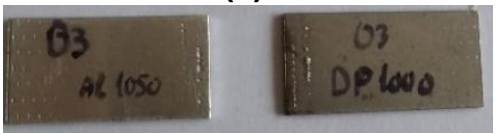

(3)

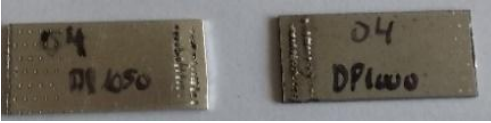

(4)

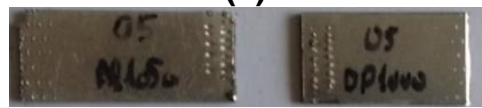

(5)

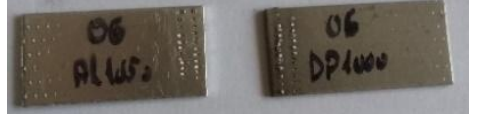

(6)

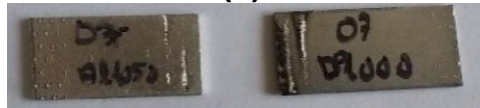

(7)

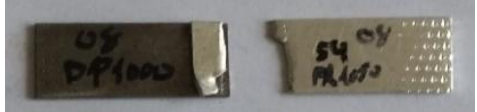

(8)

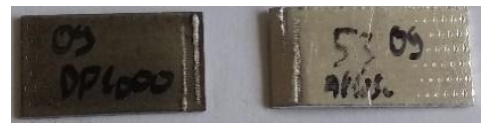

(9)

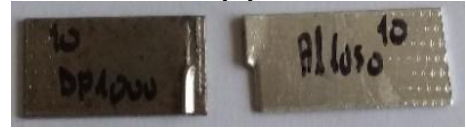

(10)

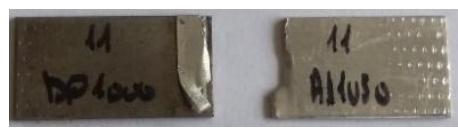

(11)

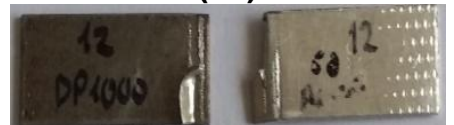

(12)

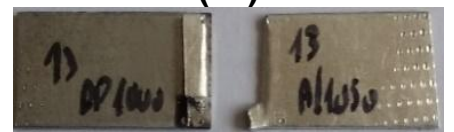

(13)

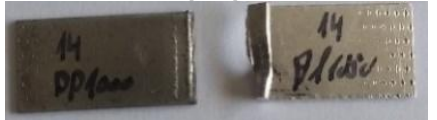

(14)

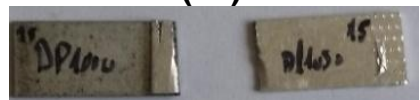

(15)

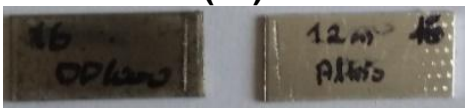

(16)

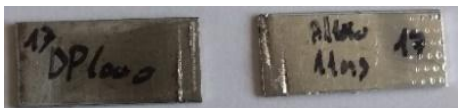

(17)

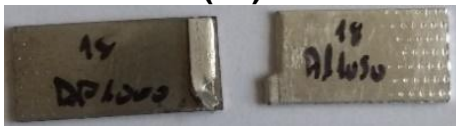

(18)

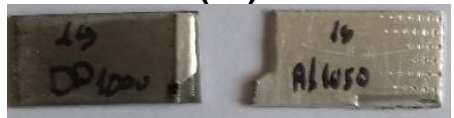

(19)

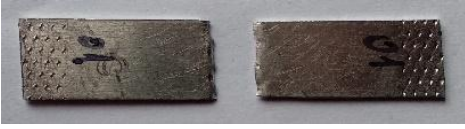

(20)

Fig. 10. Samples after tensile testing 
Fig. 11a shows the stress-strain curve for the samples where fracture occurred partially or completely through the aluminum part (true stress/strain values). On the other hand, Fig. 11b shows the samples where fracture occurred through the welding joint. In both, the reference sample stress-strain curve was included for comparison. Since Fig. 11 plots the true stress vs. true strain, the curves were only presented up to maximum stress value.

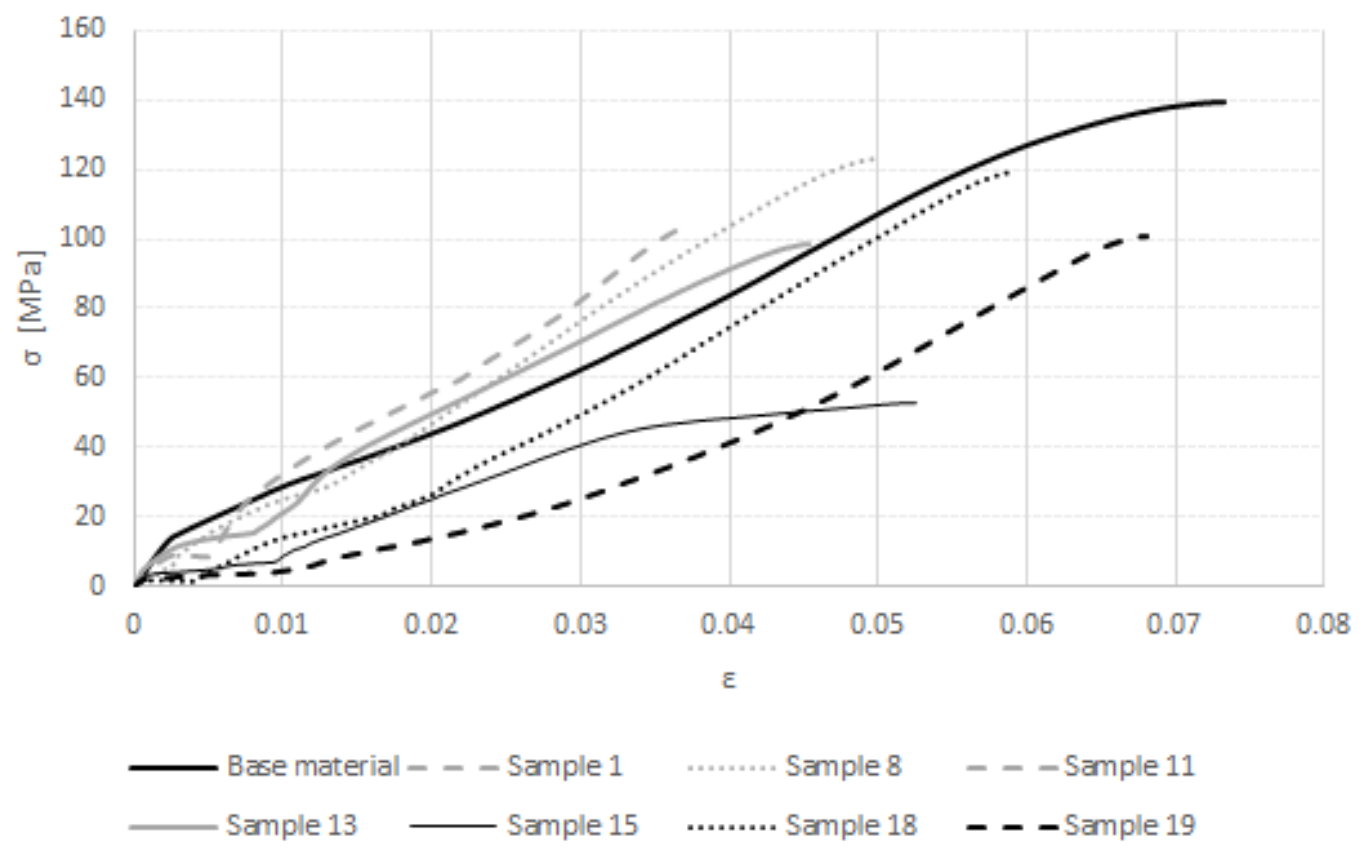

(a)

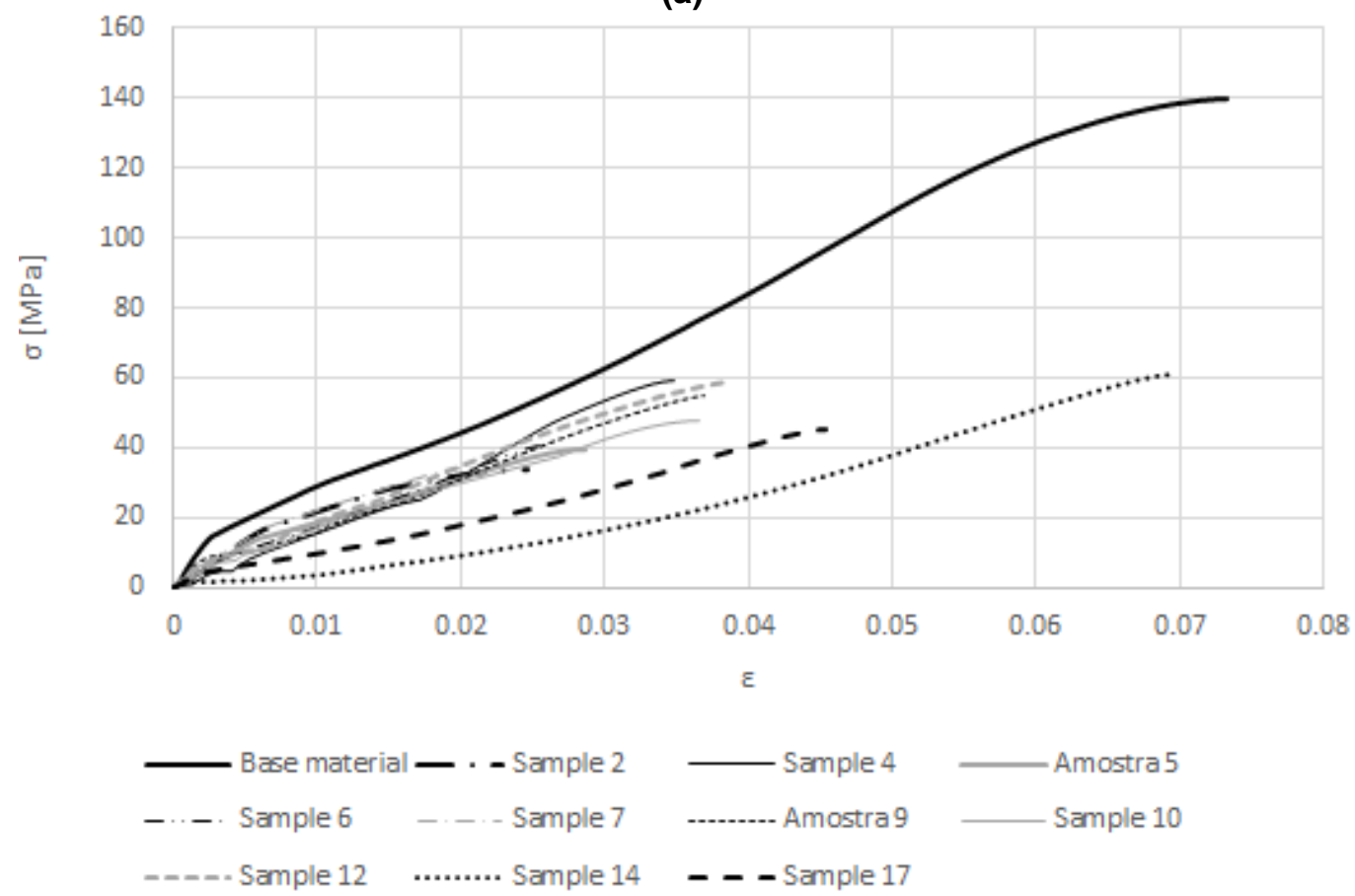

(b)

Fig. 11. True stress-strain curves for the samples where fracture occurred through: (a) the aluminum part; (b) the welding joint

An ideal welded sample would perform similarly to the original (weakest) material in terms of tensile strength and maximum elongation. Regarding tensile strength, the samples that performed better 
were samples 8 and 18 (Figs. 11 and 12). The latter had a slightly lower value but a higher strain value, thus being considered the best of this whole batch, reaching a $20 \mathrm{MPa}$ lower tensile strength and a $1 \%$ strain difference compared the reference sample. It is also worth mentioning that for sample 19 , although its maximum stress was significantly lower than samples 8 and 18, its maximum strain was closest to the reference sample. In this group, the worst sample was clearly sample 15 which had the lowest tensile strength. It could probably be justified by the excessive laser penetration on the aluminum part, causing its fragilization. Thus, an ideal laser power between 54 and 55, with a pulse duration between 13 and $15 \mathrm{~ms}$ can be herein stated.

For the samples where the welding joint did not remain intact after tensile testing, the maximum stress recorded was much lower than the one in the reference sample (at best, $80 \mathrm{MPa}$ lower). However, it is important to highlight the sample 14 strain value, which came close to the value of the reference sample. It is worth mentioning that the curves of samples 3 and 16 are not plotted in Fig. 11, since the results were irrelevant. For an exact reading of the tensile strength values, as well as their respective strain values, the following bar graphs are seen in Fig. 12.

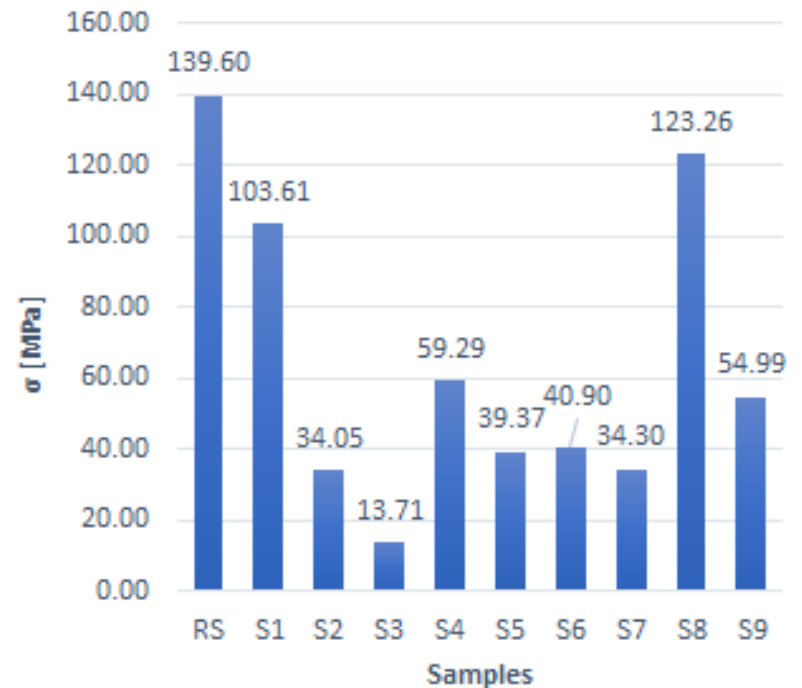

(a)

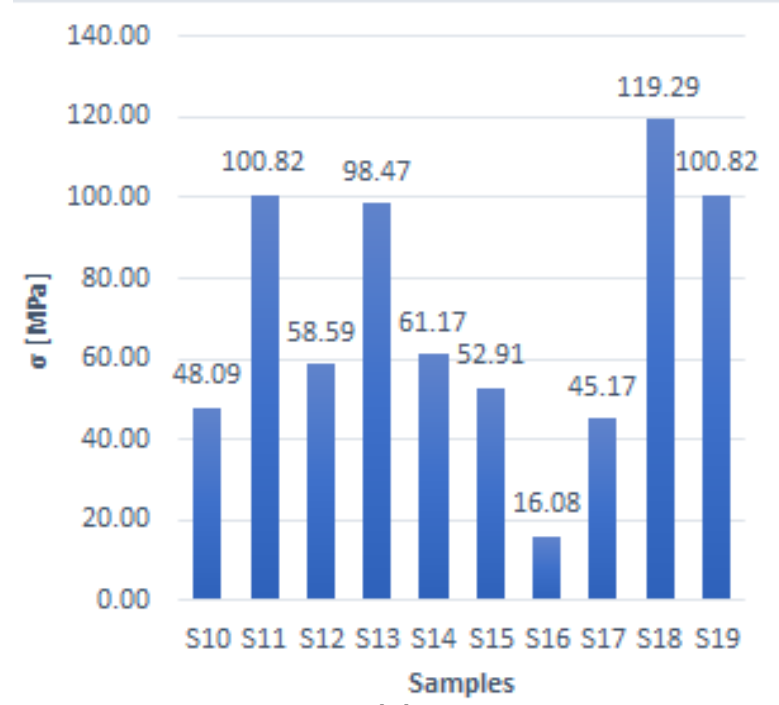

(c)

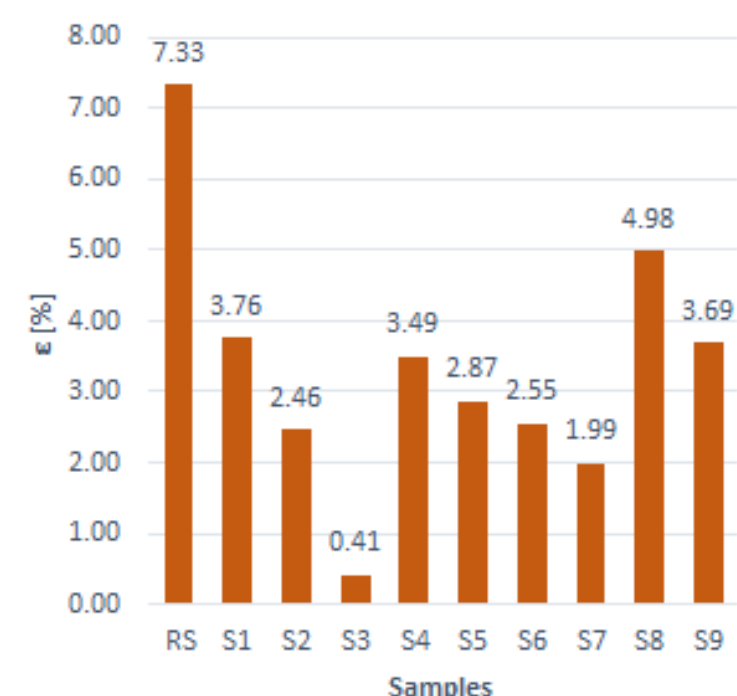

(b)

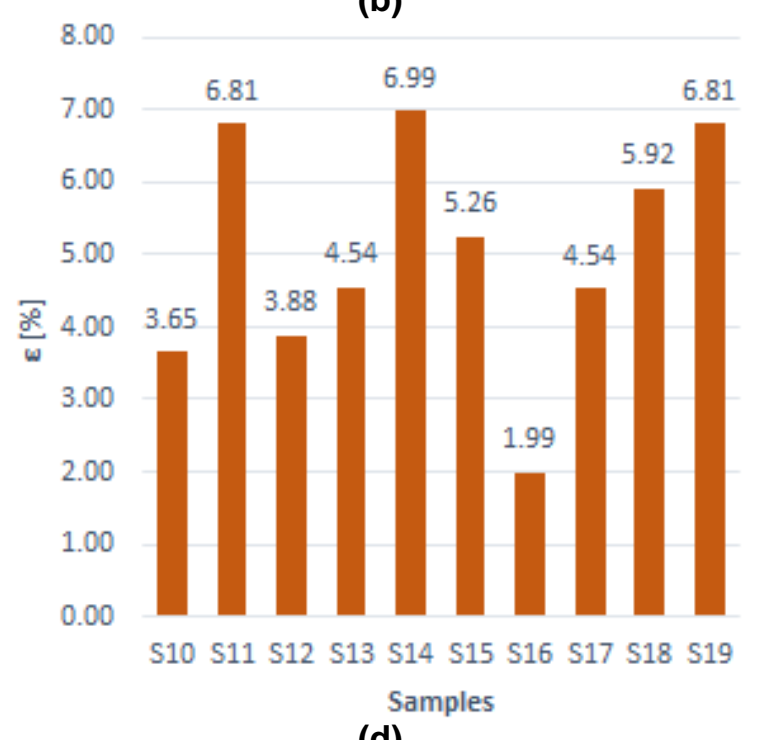

(d)

Fig. 12. Results from the tensile tests: (a) Ultimate tensile strength (samples 1 to 9); (b) Strain associated with the ultimate tensile strength (samples 1 to 9); (c) Ultimate tensile strength (samples 10 to 19); (d) Strain associated with the ultimate tensile strength (samples 10 to 19). (Note: RS means "reference sample" whereas S1 from S19 are the samples from 1 to 19) 
In terms of laser power (samples 2 to 12), the best results were obtained as this value decreased. Considering the pulse duration (samples 13 to 17), the contrary could be seen for the same value of the laser power. However, in terms of strain, the results were inconclusive without a linear behavior of any sort of pattern. Sample 18 could be considered the ideal sample, with a tensile strength and strain of only $20 \mathrm{MPa}$ and $1.4 \%$, respectively, which was lower than the reference sample. This ideal sample was repeated to evaluate its microstructure.

\subsection{Microstructure}

Figs. 13 and 14 show the observations using the optical microscope and SEM, respectively. In Fig. 13 , the welded joint is easily spotted, being observed in the way in which both metals melted and mixed in a successful way. This was also confirmed through the SEM observations in Fig. 14, where it shows the interface between the two metals. In Fig. 14b, it was possible to spot the Fe particles in the aluminum.
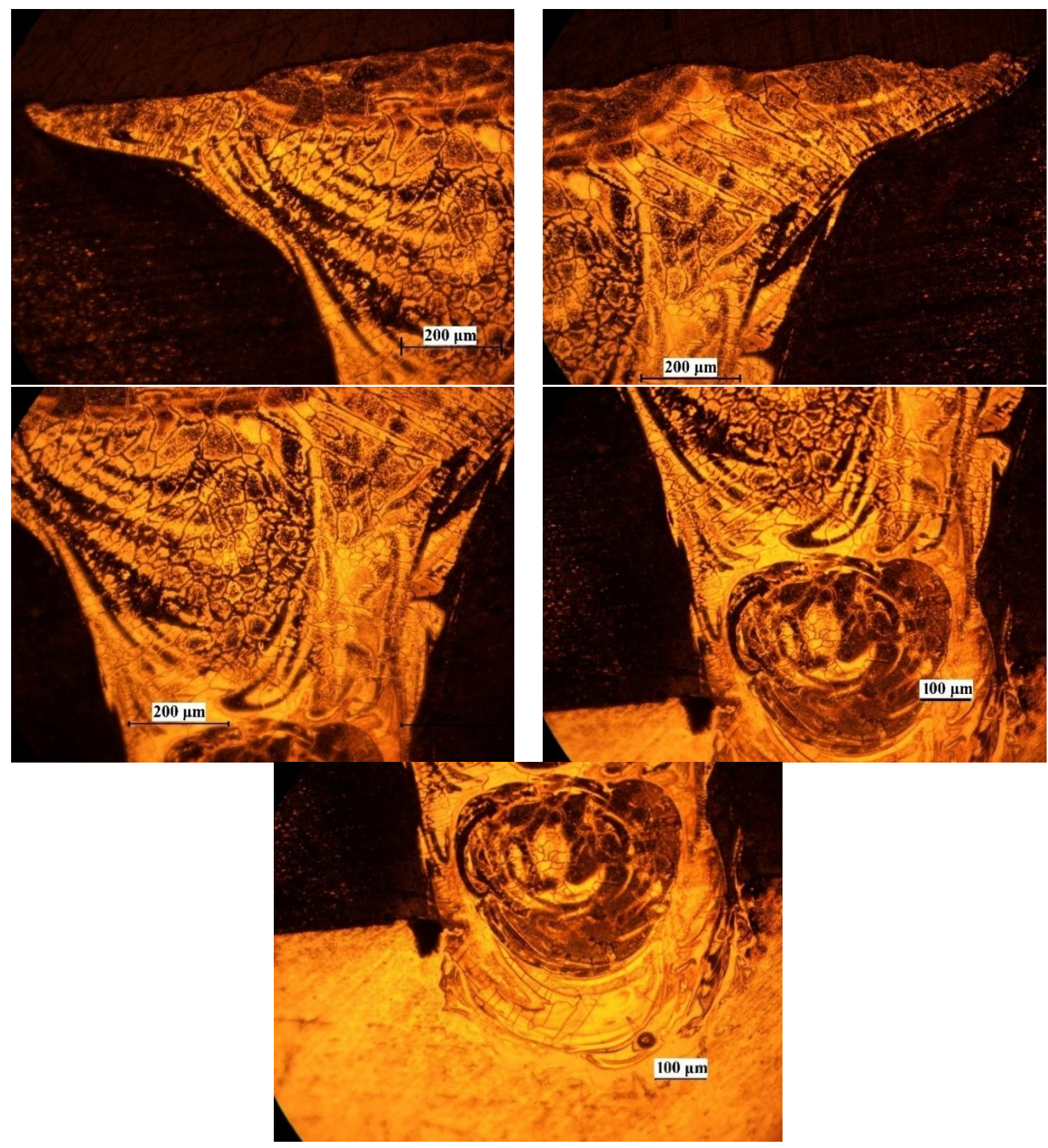

Fig. 13. Optical microscope observations of the welded zone 


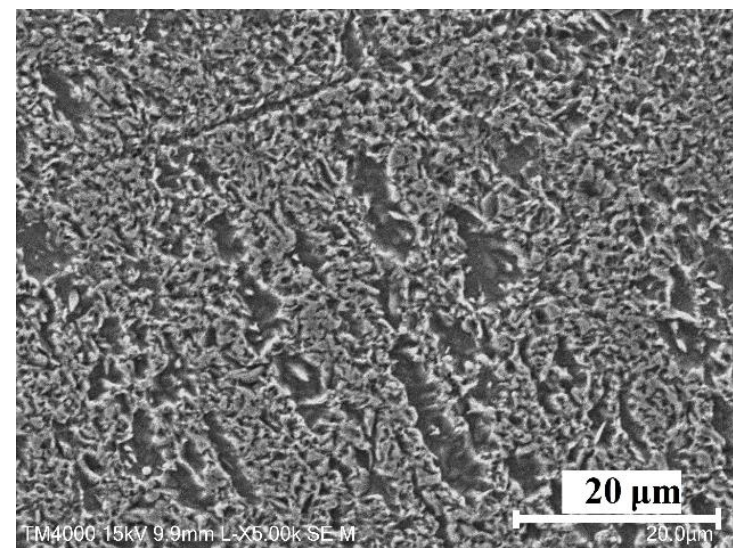

(a)

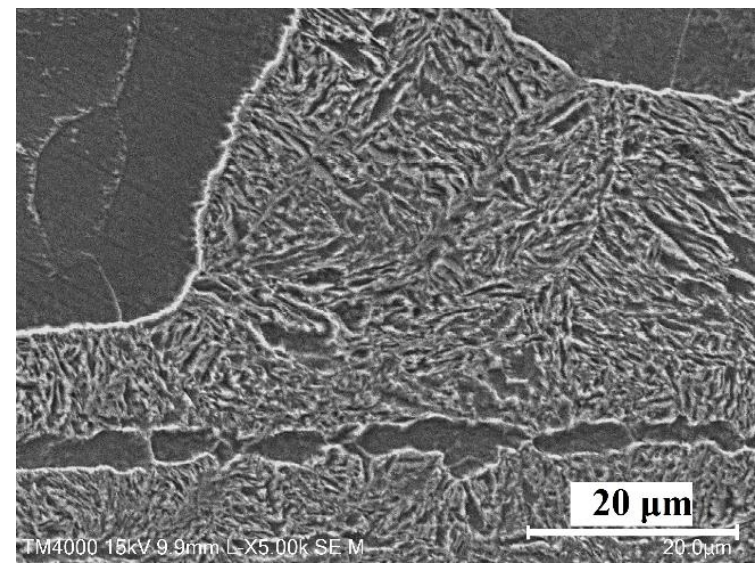

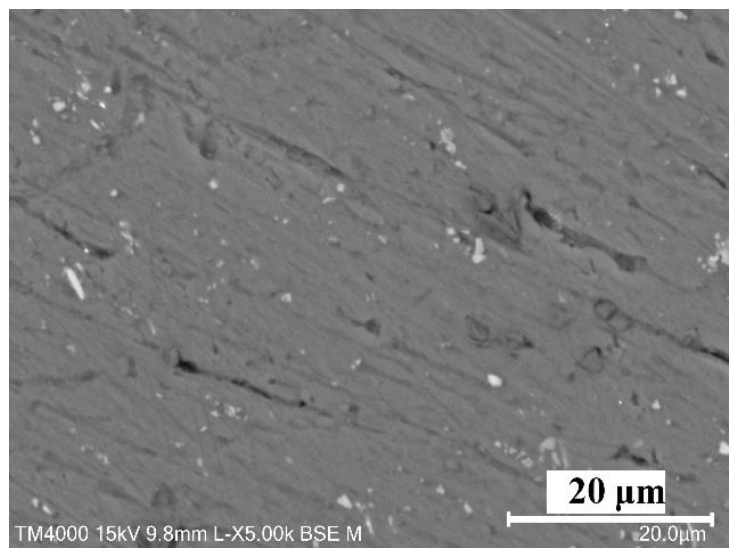

(b)

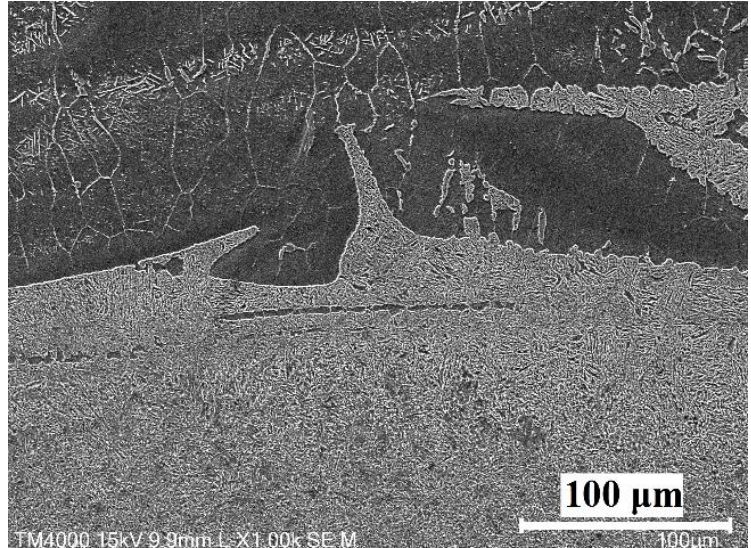

(c)

Fig. 14. Scanning electron microscope (SEM) observations: (a) Steel; (b) Aluminum; (c) Steelaluminum joint interfaces

Fig. 15 shows the BSE images collected, as well as the microstructural and compositional analysis of the welded zone. Compositions are detailed in Table 5 for a total of eight different points, six of them in the welded zone and the other two in the base materials used as the reference.
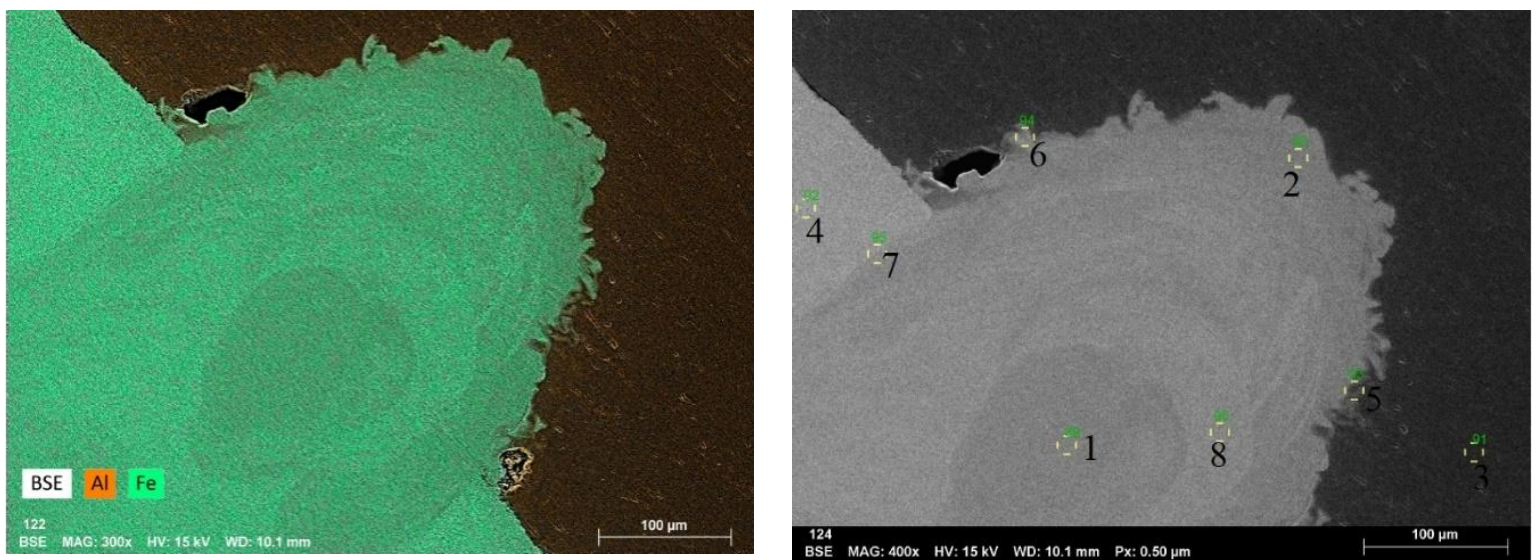

Fig. 15. Back-scattered electron detector (BSE) images with elemental composition mapping using Energy-dispersive X-ray spectroscopy (EDS) 
Table 5. Elemental composition mapping (normalized mass concentration [\%])

\begin{tabular}{llllll}
\hline Spectrum & $\mathbf{C}$ & $\mathbf{O}$ & $\mathbf{A l}$ & $\mathbf{S i}$ & $\mathbf{F e}$ \\
\hline $\mathbf{1}$ & 8.25 & 2.10 & 12.17 & - & 77.48 \\
$\mathbf{2}$ & 8.30 & 2.82 & 19.13 & 0.59 & 69.15 \\
$\mathbf{3}$ & 13.00 & 10.87 & 62.77 & 9.37 & 3.99 \\
$\mathbf{4}$ & 8.18 & 2.37 & 4.73 & - & 84.72 \\
$\mathbf{5}$ & 9.39 & 3.33 & 46.69 & - & 40.59 \\
$\mathbf{6}$ & 10.11 & 3.22 & 23.85 & - & 62.82 \\
$\mathbf{7}$ & 7.83 & 2.11 & 9.53 & - & 80.53 \\
$\mathbf{8}$ & 7.70 & 2.13 & 8.86 & - & 81.31 \\
Mean & 9.10 & 3.62 & 23.47 & 4.98 & 62.58 \\
Sigma & 1.77 & 2.97 & 20.66 & 6.21 & 27.63 \\
SigmaMean & 0.63 & 1.05 & 7.31 & 2.20 & 9.77 \\
\hline
\end{tabular}

\section{CONCLUSIONS}

In this work, the welding of dissimilar metals was performed with success. A pulsed Nd: YAG laser welding machine, the SISMA SWA300, was used to join the DP1000 steel and the AA1050. The adopted strategy was based on the lap welding of two sheet samples of each metal, since butt welding was nearly impossible due to the great disparity in terms of the thermal properties of both materials.

Even if some predicted difficulties in welding these dissimilar metals were found, a good choice of welding parameters was studied resulting in good-quality welded joints. The quality was confirmed by the results obtained in the tensile tests and in the observations performed using the optical microscope and the SEM. It is worth highlighting the sample performance, which reached tensile strengths and maximum elongations close to the weakest base metal, the AA1050.

In conclusion, it was shown that even for highly dissimilar materials, with very distinct material properties (thermal and mechanical), one can declare the success of this work. The possibility to effectively join high strength dual-phase steels with a soft, ductile 1XXX aluminum alloy opens a new range of design possibilities and attests the versatility of laser-type welding operations. The authors hope that this study can serve as a sounding base for any other future work in this area.

\section{FUNDING}

This work was supported by the projects UIDB/00481/2020 and UIDP/00481/2020 - FCT - Fundação para a Ciência e a Tecnologia; and CENTRO-01-0145-FEDER-022083 - Centro Portugal Regional Operational Programme (Centro2020), under the PORTUGAL 2020 Partnership Agreement, through the European Regional Development Fund.

\section{ACKNOWLEDGEMENTS}

Center of Mechanical Technology and Automation, Fundação para a Ciência e a Tecnologia, grant CEECIND/01192/2017.

\section{COMPETING INTERESTS}

Authors have declared that no competing interests exist.

\section{REFERENCES}

1. Sun Z, Ion JC. Laser welding of dissimilar metal combinations. J. Mater. Sci. 1995;30:42054214.

DOI: 10.1007/BF00361499 
2. Wang $P$, Chen $X, P a n ~ Q$, Madigan $B$, Long J. Laser welding dissimilar materials of aluminum to steel: An overview. Int. J. Adv. Manuf. Technol. 2016;87:3081-3090.

DOI: $10.1007 / \mathrm{s} 00170-016-8725-y$

3. Allison A, Scudamore R. Strategic Research Agenda: Joining: Joining Subplatform; 2014.

Available:http://www.joining-platform.com/documents/Joining\%20Sub-Platform\%20SRA\%20\%202014.pdf

4. Martinsen K, Hu SJ, Carlson BE. Joining of dissimilar materials. Cirp Annals. 2015;64(2):679699.

5. Katayama S. Laser welding of aluminium alloys and dissimilar metals. Weld. Int. 2004;18:618625.

DOI: 10.1533/wint.2004.3315

6. Shah LH, Ishak M. Review of research progress on aluminum-steel dissimilar welding. Mater. Manuf. Process. 2014;29:928-933.

DOI: $10.1080 / 10426914.2014 .880461$

7. Shao L, Shi Y, Huang JK, Wu SJ. Effect of joining parameters on microstructure of dissimilar metal joints between aluminum and galvanized steel. Mater. Des. 2015;66:453-458.

DOI: 10.1016/J.MATDES.2014.06.026

8. Song JL, Lin SB, Yang CL, Ma GC, Liu H. Spreading behavior and microstructure characteristics of dissimilar metals TIG welding-brazing of aluminum alloy to stainless steel. Mater. Sci. Eng. A. 2009;509:31-40.

DOI: $10.1016 /$ J.MSEA.2009.02.036

9. Kelkar A, Roth R, Clark J. Automobile bodies: Can aluminum be an economical alternative to steel? JOM. 2001;53(8):28-32.

10. Mendez PF, Eagar TW. New trends in welding in the aeronautic industry. 2 Conference of New Manufacturing Trends, Bilboa, Spain. 2002;19-20.

11. Atabaki MM, Nikodinovski M, Chenier P, Ma J, Harooni M, Kovacevic R. Welding of aluminum alloys to steels: An overview. Journal for Manufacturing Science and Production. 2014;14(2):5978.

12. Borrisutthekul R, Yachi T, Miyashita $\mathrm{Y}$, Mutoh $\mathrm{Y}$. Suppression of intermetallic reaction layer formation by controlling heat flow in dissimilar joining of steel and aluminum alloy. Mater. Sci. Eng. A. 2007;467:108-113.

DOI: 10.1016/J.MSEA.2007.03.049

13. Bouché K, Barbier F, Coulet A. Intermetallic compound layer growth between solid iron and molten aluminium. Mater. Sci. Eng. A. 1998;249:167-175.

DOI: 10.1016/S0921-5093(98)00573-5

14. Cui L, Chen H, Chen B, He D. Welding of dissimilar steel/Al joints using dual-beam lasers with side-by-side configuration. Metals. 2018;8:1017.

DOI: $10.3390 / m e t 8121017$

15. Torkamany MJ, Tahamtan S, Sabbaghzadeh J. Dissimilar welding of carbon steel to 5754 aluminum alloy by Nd:YAG pulsed laser. Mater. Des. 2010;31:458-465.

DOI: 10.1016/J.MATDES.2009.05.046

16. Sun J, Yan Q, Gao W, Huang J. Investigation of laser welding on butt joints of Al/steel dissimilar materials. Mater. Des. 2015;83:120-128.

DOI: 10.1016/J.MATDES.2015.05.069

17. Meco S, Pardal G, Ganguly S, Williams S, McPherson N. Application of laser in seam welding of dissimilar steel to aluminium joints for thick structural components. Opt. Lasers Eng. 2015;67:22-30.

DOI: 10.1016/j.optlaseng.2014.10.006

18. Corigliano $P$, Crupi $V$, Guglielmino $E$. Non linear finite element simulation of explosive welded joints of dissimilar metals for shipbuilding applications. Ocean Eng. 2018;160:346-353.

DOI: 10.1016/J.OCEANENG.2018.04.070

19. Corigliano P, Crupi V, Guglielmino E, Mariano Sili A. Full-field analysis of AL/FE explosive welded joints for shipbuilding applications. Mar. Struct. 2018;57:207-218.

DOI: 10.1016/J.MARSTRUC.2017.10.004

20. Kaya Y. Microstructural, mechanical and corrosion investigations of ship steel-aluminum bimetal composites produced by explosive welding. Metals. 2018;8:544.

DOI: $10.3390 /$ met8070544 
21. Katayama S. Laser welding of aluminium alloys and dissimilar metals. Weld. Int. 2004;18:618625.

DOI:10.1533/wint.2004.3315

22. Rana RS, Chouksey R, Dhakad K, Paliwal D. Optimization of process parameter of Laser beam machining of high strength steels: A review. Mater. Today Proc. 2018;5:19191-19199.

DOI: 10.1016/J.MATPR.2018.06.274

23. Patidar D, Rana RS. The effect of $\mathrm{CO}_{2}$ laser cutting parameter on mechanical \& microstructural characteristics of high strength steel-A review. Mater. Today Proc. 2018;5:17753-17762.

DOI: 10.1016/J.MATPR.2018.06.099

24. Chen S, Huang J, Ma K, Zhao X, Vivek A. Microstructures and mechanical properties of laser penetration welding joint with/without Ni-Foil in an overlap steel-on-aluminum configuration. Metall. Mater. Trans. A. 2014;45:3064-3073. DOI: $10.1007 / \mathrm{s} 11661-014-2241-1$

25. Zhan Y, Zhang E, Ge Y, Liu C. Residual stress in laser welding of TC4 titanium alloy based on ultrasonic laser technology. Appl. Sci. 2018;8:1997.

DOI: 10.3390/app8101997

26. Li R, Zhang F, Sun T, Liu B, Chen S, Tian Y. Investigation of strengthening mechanism of commercially pure titanium joints fabricated by autogenously laser beam welding and laser-MIG hybrid welding processes. Int. J. Adv. Manuf. Technol.; 2018.

DOI: $10.1007 / \mathrm{s} 00170-018-2922-9$

27. Fernandes FAO, Oliveira DF, Pereira AB. Optimal parameters for laser welding of advanced high-strength steels used in the automotive industry. Procedia Manuf. 2017;13:219-226.

DOI: 10.1016/j.promfg.2017.09.052

28. Smithells CJ, Colin J, Gale WF, William F, Totemeier TC. Metals Reference Book; Elsevier Butterworth-Heinemann; 2004.

29. Esmaeili A, Givi MKB, Rajani HRZ. A metallurgical and mechanical study on dissimilar Friction Stir welding of aluminum 1050 to brass (CuZn30). Mater. Sci. Eng. A. 2011;528:7093-7102. DOI: 10.1016/J.MSEA.2011.06.004

30. Wang J, Yang L, Sun M, Liu T, Li H. Effect of energy input on the microstructure and properties of butt joints in DP1000 steel laser welding. Mater. Des. 2016;90:642-649.

DOI: 10.1016/J.MATDES.2015.11.006 
Biography of author(s)

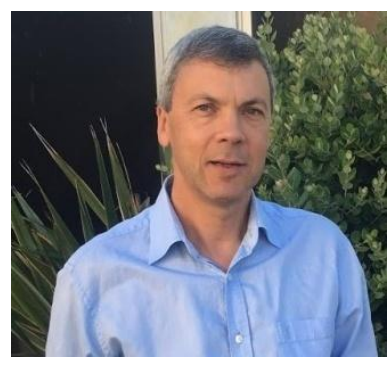

António B. Pereira

TEMA-Centre for Mechanical Technology and Automation, Department of Mechanical Engineering, University of Aveiro, Campus de Santiago, 3810-193, Aveiro, Portugal.

He has $\mathrm{PhD}$ and BSc in Mechanical Engineering by University of Aveiro. He is the Founding shareholder and Director of Martifer Group (ca. 3500 employees) (1990-1999) who was responsible for the planning and production of about 500 steel structures and industrial equipment with a total amount exceeding 100 million euros. Since 2000 he has been a professor at the University of Aveiro, where he held management positions in the Department of Mechanical Engineering - Executive Committee. He is currently Director at the Centre for Mechanical Technology and Automation (TEMA), where he also coordinates the Research Infrastructure included in the National Roadmap. Under his coordination, TEMA was also selected to appear on the European network of institutions considered to be relevant within the scope of Key Enabling Technologies. His main research areas focus on the study of materials and processes, collaborating in 24 research projects, and having been Principal Investigator for 14 of them. He has more than 60 papers published in $\mathrm{SCl}$ journals and more than 40 papers presented in international conferences. His h-index at Scopus is 20 with more than 1200 citations.

\section{(C) Copyright (2021): Author(s). The licensee is the publisher (Book Publisher International).}

\section{DISCLAIMER}

This chapter is an extended version of the article published by the same author(s) in the following journal. Metals, 9(102): 1-16, 2019. 